Titulo do Trabalho

\section{RESÍDUOS SÓLIDOS URBANOS: DE PROBLEMA SOCIAL À FONTE DE RENDA}

Autor principal

Tiago Borges Ferreira

Nomes dos Co autores

Grégori Henrique Soares; Diego Lula

Nomes dos Orientadores

Tiago Zanquêta de Souza; Aristóteles Teobaldo Neto

Instituição

Universidade de Uberaba - UNIUBE

E-mail de contato

tiago_bferreira@hotmail; gregori.soares@msn.com; diego_lula@hotmail.com; tiago.zanqueta@uniube.br; teobaldoneto@yahoo.com.br

Palavra chave

Aterro Sanitário. Disposição final. Lixão

\section{INTRODUÇÃO}

Os resíduos sólidos têm sido ao longo do passar dos anos, um dos grandes entraves para um pleno desenvolvimento socioeconômico da humanidade. Desde a fase em que o homem se fixou em uma região, deixando de ser nômade, começou a produzir seu alimento e a domesticar animais, gerando a partir disso o acúmulo de resíduos, de origem orgânica, como alimentos descartados, apodrecidos, dentre outros.

Por uma questão de necessidade, o ser humano começou a pensar formas de descarte e tratamento de resíduos, com a finalidade de melhorar as condições sanitárias de sobrevivência. Desde o desenvolvimento de uma vida fixa e começo de uma vida 


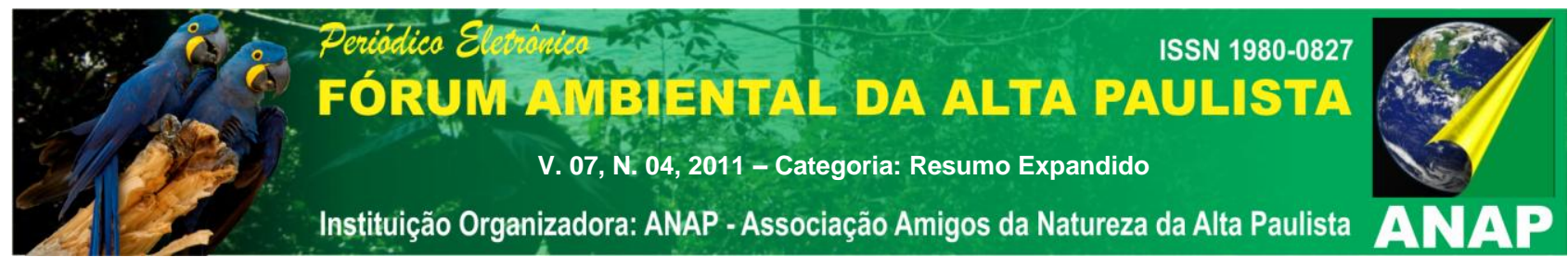

organizada em grupos sociais, os resíduos passaram a se constituir fatores de impactos a áreas verdes e também a corpos hídricos. Ainda em pequena quantidade, esses resíduos eram decompostos naturalmente, e, consequentemente ao aumento destas populações, a natureza por si só não conseguia mais decompor esse material. Dessa forma, foi se desenvolvendo algumas formas de disposição mais adequadas, como o aterramento, técnica que podia (e ainda pode) ser prejudicial ao solo e corpos hídricos subterrâneos.

A situação de descarte inadequado dos resíduos tornou-se um problema ainda maior quando os centros urbanos começaram a receber as populações que migravam do campo para a cidade, em virtude do êxodo rural, desencadeado a partir da revolução industrial, no século XVIII (na Europa) e anos mais tarde nos países latino-americanos, como no Brasil. Além da população que já ocupava condomínios e prédios, começou-se a também a formação de cortiços e favelas, fato determinante para a má condição de saneamento e higiene à época. Á medida em que se aumentou a quantidade de pessoas por unidade de área, concentrou-se também a quantidade de resíduos gerados. Estava instaurada a era do consumo, que automaticamente maximizou a geração de resíduos, implicando num dos maiores problemas das grandes cidades.

Então esses resíduos foram sendo acumulados em áreas periféricas, nos conhecidos lixões, que além de todos os problemas ambientais de percolação, (contaminação de solos e corpos hídricos), acarreta um grande problema social, pois a população mais carente encontra neles sua única fonte de renda e alimento.

Assim, o desenvolvimento de uma consciência ecológica e social, em relação aos lixões, começou a ser desenvolvida no Brasil, mas caminha a passos lentos, pois produz atualmente cerca de 120 milhões de toneladas de resíduos por ano, sendo $75 \%$ disposto nos lixões, cerca de $15 \%$ colocados em aterros controlados e somente $10 \%$ em aterros sanitários (BROLLO, 2001 apud GUIZARD, 2006).

\section{OBJETIVO GERAL}

Analisar as atuais condições de saneamento e descarte de resíduos sólidos urbanos (RSU). 


\section{OBJETIVOS ESPECÍFICOS}

Avaliar a importância de uma usina de triagem e compostagem de resíduos sólidos, analisando in loco a situação de Uberaba-MG.

\section{METODOLOGIA}

A metodologia do presente trabalho é estritamente quali-quantitativa. Consistiu basicamente de levantamento e análise teorico-bilbiográfica, conforme indica Ludke e André (1986), além de visitas de campo, no Aterro Sanitário de Uberaba.

\section{RESULTADOS}

O município de Uberaba está situado em Minas Gerais, mais precisamente no triângulo mineiro, com uma população estimada em 288.235 habitantes (IBGE, 2010). O nome Uberaba, segundo alguns autores, vem do tupi e significa rio claro ou rio brilhante.

Atualmente a cidade conta com um aterro sanitário, onde são dispostos todos os resíduos sólidos urbanos, excluindo-se somente os resíduos da construção civil. Esta forma de disposição contraria a Lei 12.305/10 - Política Nacional de Resíduos Sólidos (PNRS), que traz em seu art. $7^{\circ}$ os objetivos desta, os quais pregam em sua maioria a segregação, reutilização, reciclagem e gestão integrada destes resíduos.

A cidade de Uberaba produz por dia segundo o RIMA (2010), 199.991 toneladas de resíduos sólidos, sendo eles: domésticos (182.320 t.), de varrição (10.365 t.) e sépticos (7.306 t.), ou melhor, $91,16 \%, 5.19 \%, 3.65 \%$ respectivamente.

Segundo esta mesma fonte, esses resíduos são formados por $62,33 \%$ de material orgânico, $8,98 \%$ de material plástico, $14.17 \%$ de papeis e $14.62 \%$ de outros materiais.

Com os dados supracitados, onde na pior das hipóteses, deveria se aproveitar somente material orgânico e cerca de $50 \%$ dos papeis e dos plásticos, seria aterrados 


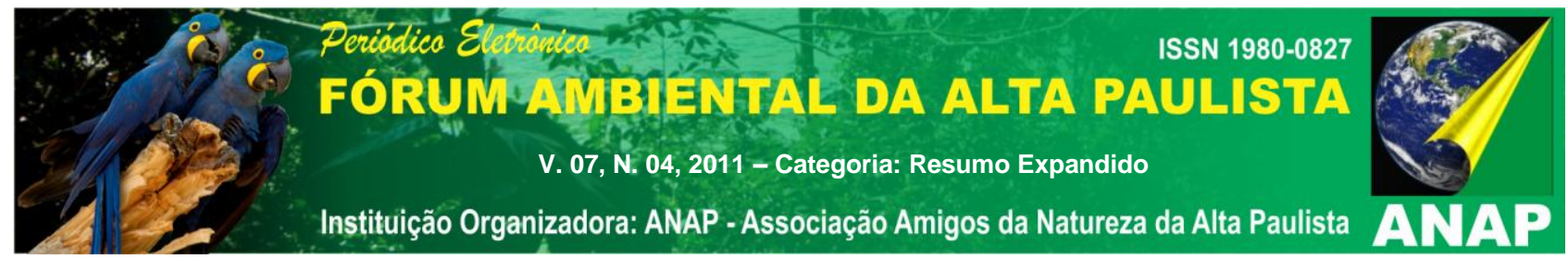

somente $26,195 \%$ dos resíduos que se aterram hoje. Isso daria uma vida útil de aproximadamente 3 (três) vezes maior ao que se tem hoje (15 anos). Em anos isso representaria ao aterro de Uberaba um acréscimo de 60 anos. Sem se contabilizar a receita gerada pelos reciclados e composto orgânico, o próprio RIMA tem cálculos efetuados com rendas superiores a $\mathrm{R} \$ 10.000$ (dez mil reais) por mês.

É bom ainda ressaltar que a tecnologia de aterro sanitário consiste em instalações criadas para haver uma disposição segura dos resíduos sólidos gerados pela população, industrias e outras fontes, com o objetivo de minimizar os impactos ambientais, sociais e econômicos de um determinado centro urbano/industrial. Os aterros são obras de engenharia, com impermeabilização do solo, cálculos matemáticos e planejamento para sua instalação. O controle ambiental no seu entorno é muito rígido, com averiguações em solo, água e ar.

Já as usinas de triagem são unidades onde são aglomerados todos os resíduos sólidos urbanos coletados, aglomera para posterior separação, fazendo uma "triagem" dos materiais que compõe o mesmo, dando o destino mais adequado a cada um deles.

A quantidade de cada subproduto é muito relativa, variando de local para local, dependendo da cultura e forma de consumo. Segundo Teixeira (2008), uma unidade no bairro do Cajú, no Rio de janeiro, recebe cerca de 8.200 toneladas de resíduos por dia, dos quais, $7,6 \%$ é reciclado e 13,5\% é transformado em composto orgânico, o restante deste volume recolhido possivelmente será destinado a um aterro sanitário.

Em Minas Gerais, a Lei Estadual nº 12.040/95, substituída posteriormente pela Lei 13.803/2000, incentiva as administrações municipais a buscar soluções para os problemas socioambientais que se relacionam com os resíduos sólidos urbanos (RSU), (PRADO FILHO,2007), é a famosa lei Robin Hood, pois trata o montante da arrecadação, podendo os municípios pobres também se beneficiarem, bastando para isso apresentarem projetos, e uma das formas de destinação de RSU mais praticada e talvez a mais correta no aspecto socioambiental.

Segundo Prado Filho (2007), às usinas de tratamento, reciclagem e compostagem de resíduos sólidos domésticos, em Minas Gerais existem hoje 55 unidades, caracterizadas como unidades bastante simples, onde se faz a triagem manual dos materiais recicláveis e a compostagem da fração orgânica. 


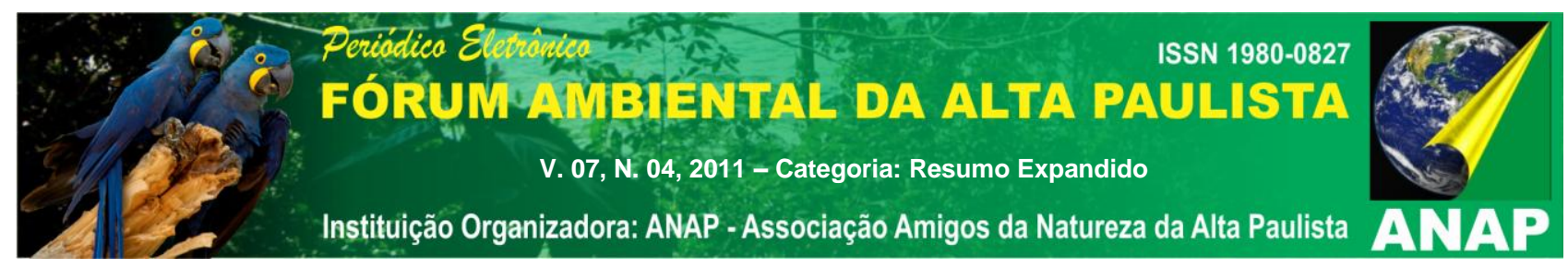

\section{CONSIDERAÇÕES FINAIS}

Com as principais características levantadas, considerando o caso de UberabaMG, torna-se evidente as vantagens da usina de triagem e compostagem em auxilio ao aterro, levando em consideração alguns aspectos:

- Colocação no mercado de trabalho a mão de obra dos catadores de recicláveis e a usina precisa dessa mão de obra.

- O aproveitamento dos materiais orgânicos para produção de composto orgânico.

- Reaproveitamento dos recicláveis.

- Aumento da vida útil do aterro

Só assim essa obra estaria satisfazendo todos os aspectos propostos, uma disposição que equilibra o social, atendido pela usina ao empregar os catadores, 0 ambiental, ao monitorar por completo o aterro, assim como é efetuado, e o econômico, quanto obtivesse renda deste meio, não se tornando apenas mais uma despesa municipal mais sim uma forma de obtenção de receita.

\section{REREFÊNCIAS BIBLIOGRÁFICAS}

BRASIL. Lei $n^{\circ} 12.305$ de 02 de agosto de 2010. Institui a Política Nacional de Resíduos Sólidos. Disponível em: < http://www.mma.gov.br/port/conama/legiabre.cfm?codlegi=636> Acesso em: 07 de setembro de 2011

GUIZARD, João Batista Ricardo et al. Aterro sanitário de Limeira: Diagnóstico ambiental. Espírito Santo do pinhal-SP v.3, n.1, p.072-081, jan/jun 2006

IBGE, Resultados do senso 2010. Disponível em :< http://www.ibge.gov.br/home/estatistica/populacao/censo2010/resultados_dou/MG2 010.pdf>. Acesso em 30 Junho 2011

LÜDKE, Menga, ANDRÉ, Marli E. D. A.. Pesquisa em educação: abordagens qualitativas. São Paulo: EPU, 1986. 99 p. 


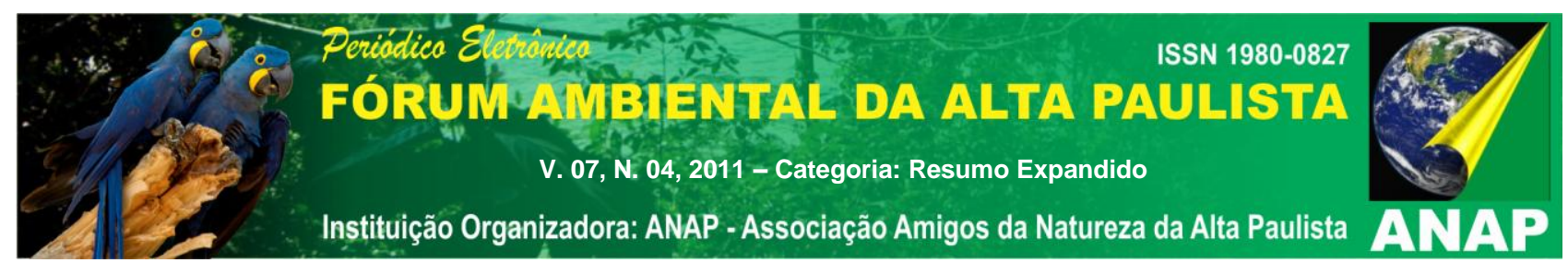

PRADO FILHO, José Francisco do and SOBREIRA, Frederico Garcia. Desempenho operacional e ambiental de unidades de reciclagem e disposição final de resíduos sólidos domésticos financiadas pelo ICMS Ecológico de Minas Gerais. Eng. Sanit. Ambient. [online]. 2007, vol.12, n.1, pp. 52-61.

RIMA, Resumo do Relatório de Impacto Ambiental, situado na sede do aterro sanitário de Uberaba-MG. Av Filomena Cartafina, próximo ao bairro rural da baixa. Consulta em: maio de 2010

TEIXEIRA, Adair Ferreira Motta et al. Controle de mosca doméstica em área de disposição de resíduos sólidos no Brasil. Eng. Sanit. Ambient. [online]. 2008, vol.13, n.4, pp. 365-370. 